\title{
Evaluation of the mulch films biodegradation in soil: A methodological review
}

\author{
Matteo Francioni, Ayaka Wenhong Kishimoto-Mo, Shun Tsuboi, Yuko Takada Hoshino \\ Institute for Agro-Environmental Sciences, National Agriculture and Food Research Organization, \\ Tsukuba, Ibaraki, Japan
}

\author{
Highlights \\ - Most of the analysed studies were carried out under laboratory conditions. \\ - Biodegradation was primarily estimated by indirect methods (visual analysis, mass loss, and spectroscopy). \\ - Despite being a key factor in biodegradation, soil characteristics were not described in many papers. \\ - Indirect methods can be useful indicators for open field studies, but they cannot prove the biodegradation of materials. \\ - Indirect methods should always be coupled with direct methods ( $\mathrm{CO}_{2}$ evolution) or using films proved to be biodegradable in soil.
}

\author{
Correspondence: Matteo Francioni, Institute for Agro-Environmental \\ Sciences, National Agriculture and Food Research Organization, \\ Tsukuba, Ibaraki 305-8604, Japan. \\ Tel.: +81.29.838.8194. \\ E-mails: furanchionim090@affrc.go.jp; \\ matteofrancioni86@gmail.com
}

Key words: Bioplastics; $\mathrm{CO}_{2}$; methodology; mulching; polyesters.

Contributions: MF, AWKM, ST, YTH, conceptualisation and methodology; MF, formal analysis, data curation and writing; MF, ST, AWKM, YTH writing-review and editing; AWKM, YTH, resources, project administration, funding acquisition, and supervision.

Acknowledgements: this work was performed by Demonstration Project for a Plastics Resource Circulation System toward a Decarbonized Society (FY2019-FY2021), which was funded by the Ministry of the Environment of Japan.

Conflict of interest: the authors declare no potential conflict of interest.

Received for publication: 22 June 2021.

Revision received: 5 October 2021.

Accepted for publication: 28 October 2021.

C) Copyright: the Author(s), 2022

Licensee PAGEPress, Italy

Italian Journal of Agronomy 2022; 17:1936

doi:10.4081/ija.2021.1936

This article is distributed under the terms of the Creative Commons Attribution Noncommercial License (by-nc 4.0) which permits any noncommercial use, distribution, and reproduction in any medium, provided the original author(s) and source are credited.

Publisher's note: All claims expressed in this article are solely those of the authors and do not necessarily represent those of their affiliated organizations, or those of the publisher, the editors and the reviewers. Any product that may be evaluated in this article or claim that may be made by its manufacturer is not guaranteed or endorsed by the publisher.

\begin{abstract}
Plastic mulch films are widely used in agriculture, but most are not biodegradable in soil. Biodegradable mulch films are blends of different polymers whose composition ratios vary notably from one product to another. Their degradation rates vary significantly according to the physio-chemical characteristics of the product and according to the properties of the soil and its microbial activity. This review aims to provide an overview of the methods used to estimate the biodegradation performances of biodegradable plastics in the soil. In line with this objective, 80 papers were selected and systematically analysed to extract information on the characteristics of the soil used in the experiments, the type of polymer analysed, and the methods used to estimate biodegradation in the soil environment. Our systematic analysis showed that studies were carried out under both laboratory-controlled and open-field conditions, with different approaches involving visual analysis, mass loss measurements, spectroscopy, and $\mathrm{CO}_{2}$ measurements. Linear estimation of biodegradation performance for four of the most common biodegradable polymers (i.e., polybutylene succinate, polybutylene succinate-co-adipate, polylactic acid, and polybutylene adipate-co-terephthalate), either pure or blended, showed an extensive range of results that appear only partially comparable. Furthermore, many of the analysed papers did not report soil characteristics at all, despite soil being one of the most important factors in the biodegradation process. Although methodologies for estimating biodegradation are well developed, at least under laboratory-controlled conditions, there is a need for a shared methodology to make results comparable among different experiments. Within such a shared methodology, visual analysis or mass loss measurements, despite not being able to prove the biodegradation of polymers scientifically, should not be discarded a priori as they might be valuable indicators, especially for open-field experiments. When using indirect biodegradation indicators such as visual analysis or mass loss, it is necessary to couple them with $\mathrm{CO}_{2}$ measurements or use materials whose biodegradability in the soil environment has already been tested.
\end{abstract}




\section{Introduction}

\section{The use of plastics in agriculture: from polyethylene- based plastic to biodegradable plastic}

Plasticulture refers to the use of plastic in the agricultural sector, including its use for greenhouse covers, row tunnels, films for solarisation or fumigation, packaging, irrigation tubes, flowerpots, and many other items (Kasirajan and Ngouajio, 2012; Malinconico, 2017). The amount of plastic used for agriculture application exceeds 2 million tons per year, with most consumption in Asia, followed by Europe, especially in regions within the Mediterranean basin (Kyrikou and Briassoulis, 2007). Plastic mulch films are widespread worldwide and currently account for the majority of the plastic used in agriculture (Kasirajan and Ngouajio, 2012). According to Brodhagen et al. (2015), one hectare of plastic-mulched ground contains approximately 5,000 $\mathrm{m}^{2}$ of mulch film, roughly corresponding to $100 \mathrm{~kg}$ of plastic material laid on the soil during each cropping cycle. Synthetic plastic films are mainly made of low-density polyethylene, a polymer that shows excellent properties in terms of chemical resistance, durability, flexibility, ease of processing, and affordability (Kasirajan and Ngouajio, 2012). Proper mulching with plastic films has positive effects on crop yields mainly derived from improved soil temperatures and/or moisture and from efficient weed control (Malinconico, 2017; Martín-Closas et al., 2017; Bandopadhyay et al., 2018). Given that polyethylene-based mulch films do not naturally decompose in the soil (at least not in a reasonable amount of time), they need to be removed from the fields and disposed of somewhere (Kyrikou and Briassoulis, 2007; Kasirajan and Ngouajio, 2012; Briassoulis and Degli Innocenti, 2017). Undeniably this is a considerable problem both from the perspective of farmers' effort in removal (which might be considered an economic cost and as a $\mathrm{CO}_{2}$-emission cost) and in terms of accumulation of nondegradable plastics in the environment (MartínClosas et al., 2017). Unfortunately, the total removal and recycling of used polyethylene mulch films appear to be unfeasible since used materials are practically inseparable from soil debris and crop residues (Kasirajan and Ngouajio, 2012). Moreover, plastic deterioration by abiotic factors (i.e., weathering) occurs, and a certain fraction of the film will always remain in the environment (MartínClosas et al., 2017; Wei and Zimmermann, 2017; Bandopadhyay et al., 2018). The first types of 'degradable' plastic commercialized during the 1970s and 1980s were wrongly named 'biodegradable' when they were only 'oxo-degradable'; furthermore, they were expensive and characterized by unpredictable breakdown (Kasirajan and Ngouajio, 2012). To solve such problems, research over the last few decades has focused on the development of potentially biodegradable plastics products with properties as good as those of conventional plastics (Tokiwa et al., 2009; Kasirajan and Ngouajio, 2012; Malinconico, 2017; Wei and Zimmermann, 2017; SAPEA, 2020).

\section{Key features of biodegradable plastics used in agriculture}

It must be pointed out that the term 'bio-plastic', which is commonly used, might generate confusion or misunderstandings. While 'bio-based plastic' can be defined as 'plastic that contains organic carbon obtained from renewable resources such as crops', 'biodegradable plastic' is composed of polymers that can be degraded by microorganisms naturally present in a specific environment (e.g., agricultural soil). However, the biodegradation of such polymers does not depend on the provenance of their carbon
(Sanders et al., 2019). Indeed, not all bio-based plastics are biodegradable, while some fossil-based plastics are (Tokiwa et al., 2009; SAPEA, 2020). Whether bio-based or fossil-based, biodegradable plastics are mainly made of aromatic or aliphatic polyesters that have hydrolysable ester bonds within their polymer chain structure (Kasirajan and Ngouajio, 2012). Under aerobic conditions, fungi and bacteria can break the polymer chains at specific locations and use them as a source of energy, ultimately transforming them into $\mathrm{CO}_{2}$, water, and biomass (Wei and Zimmermann, 2017).

Three key steps can be identified in the biodegradation process of plastics: i) the colonization of the polymer surfaces by soil microorganisms; ii) the enzymatic depolymerisation of the polymer by extracellular hydrolases secreted by the colonising microorganisms; iii) the microbial utilisation of the oligomeric and monomeric hydrolysis products that are released from the polymer (Sander 2019). However, abiotic degradation might represent a crucial step in the biodegradation of some polymers that first hydrolysed abiotically (i.e., polylactic acid) and are only later utilised by microorganisms (Gorrasi and Pantani, 2017). Thus, the biodegradability of mulch films (and also of polymers in general) depends on the action and interaction of abiotic factors (e.g., soil temperature, moisture, $\mathrm{pH}$, available nutrients) and biotic factors (e.g., enzyme activity, presence or abundance of certain microorganisms) as well as on the characteristics of the polymer (e.g., crystallinity, morphology, crosslinking) (Kasirajan and Ngouajio, 2012).

Commercially available biodegradable mulch films are blends of different polyesters and starch whose composition ratios vary notably from one product to another. In these blends, specific amounts of additional components such as plasticisers or colourisers are always added during manufacturing (Bandopadhyay et al., 2018). Among the most important polyesters used to produce commercial film blends are polybutylene succinate (PBS), polybutylene succinate-co-adipate (PBSA), polylactic acid (PLA), and polybutylene adipate-co-terephthalate (PBAT) (Brodhagen et al., 2015). PBAT is the most used polyester in recent biodegradable mulch products, and, similarly to PBSA, it is derived from petroleum. Although PBS was previously only a petroleumderived product, it has recently become possible to produce biobased PBS (Xu and Guo, 2010). All of the polyesters mentioned above are generally considered biodegradable. However, the rates and levels of their biodegradability are highly dependent on their morphology (e.g., crystallinity) and chemical structure (e.g., ease of bond breaking, molecular weight), the types and numbers of microorganisms that can decompose each chemical structure, and whether the environment is suitable for the microorganisms to secrete degrading enzymes.

\section{The biodegradation of plastics in different environments}

The biodegradation of plastics can occur in different environments such as in wastewater, sewage sludge, marine, compost, and soil environments (Kjeldsen et al., 2019). However, the paths by which biodegradable plastics undergo biodegradation are different and mainly regulated by the presence or absence of oxygen and the temperature of the environment. For example, the composting environment is substantially different from the soil environment because it reaches temperatures above the range tolerated by mesophilic organisms in the soil and significantly affects inhabiting microorganisms (SAPEA, 2020). Thus, the degradation of a specific biodegradable polymer is generally faster under composting than in the soil. Furthermore, under anaerobiotic and methanogenic conditions, $\mathrm{CH}_{4}$ is released in addition to $\mathrm{CO}_{2}$ dur- 
ing biodegradation. That can happen under composting and other environments such as controlled digestion systems or landfills. In these systems, the lack of oxygen and high temperature creates optimal conditions for biodegradable plastics to be degraded by thermophilic microorganisms, with which controlled digestion systems are also often inoculated (Quecholac-Piña et al., 2020). Most of the soil where mulch films are used is a very different biodegradation environment from the ones as mentioned above because conditions are aerobic for most of the time (or at least anaerobic conditions are very rare and never occur for long periods), and it has a mesophilic temperature range.

Mulching films undergo two distinct phases in their degradation process. The first one begins when the film is placed on the soil, often coinciding with the sowing or transplanting of the crop. In this phase, which lasts a few months, the films undergo mainly an abiotic degradation where the action and interaction of UV radiation, rain, temperature, moisture, and wind (i.e., the film weathering) can modify the characteristics of the polymers (e.g., crystallinity, morphology, crosslinking) and play a key role that influences the next phase. The second phase occurs after the mulch films burial, which generally occurs by soil tillage at the end of the crop cycle. This is the phase where the biotic degradation of mulch films mainly takes place and where soil microorganisms colonise the surface of the mulch film, secrete extracellular enzymes to depolymerise it, and finally use the obtained oligomers and monomers for their metabolic activities, releasing $\mathrm{CO}_{2}, \mathrm{H}_{2} \mathrm{O}$, and new microbial biomass (Sander 2019) (Figure 1).

For bio-scientists, such as crop, soil, or microbial scientists, one of the key aspects of soil is that it is far from being a 'standard environment' as might be, for example, 'standard composting' environment. Indeed, agricultural soils can differ greatly in physicochemical and microbiological characteristics, even if they are located at close range. For example, if the same soil was managed differently over a long period (e.g., different tillage regimens and/or manure application for decades), this could influence the activity and presence of crucial microbial degraders and thus its degradation potential. Therefore, the decomposition of biodegradable films can vary from soil to soil, making it difficult for farmers to choose the most suited biodegradable film for their cropping system. For example, Yamamoto-Tamura et al. (2015) reported that the same PBSA film was degraded in eleven Japanese agricultural soils at different rates. They suggested that the biodegrading ability of the soil was correlated with the different soil fungi populations and related esterase activity. Other examples of different performances of the same biodegradable films buried in soils with different microbial activities, mainly fungi, were reported by Zhang et al. (2019) for PLA:PBAT mulches, by Hoshino et al. (2001) for PLA, PBS, and PBSA, and by Li et al. (2014) and Šerá et al. (2016) for commercial biodegradable films. However, even within the same soil environment, the estimated degradation rates of biodegradable plastics might change depending on whether the study is carried out under open-field conditions or laboratory-controlled conditions. In the latter case, although it is possible to control the main variables that influence biodegradation (i.e., soil water content and temperature of incubation), it appears to be impossible to replicate all variables found under open-field conditions. At the same time, researchers, farmers, and policymakers would be more interested in results obtained under open-field conditions because that is where the biodegradable mulch will be used and where it is meant to be disposed of. Even if it is conceivable that film biodegrading could be slower in the open field than under laboratory conditions, there are several variables to be considered that can influence the biodegradation process (e.g., the effect of repeated tillage and/or fertilization rates and types).

Several national and international standards have been created recently to make experiments as replicable as possible. The main standards and methods included will be briefly introduced in the next section.

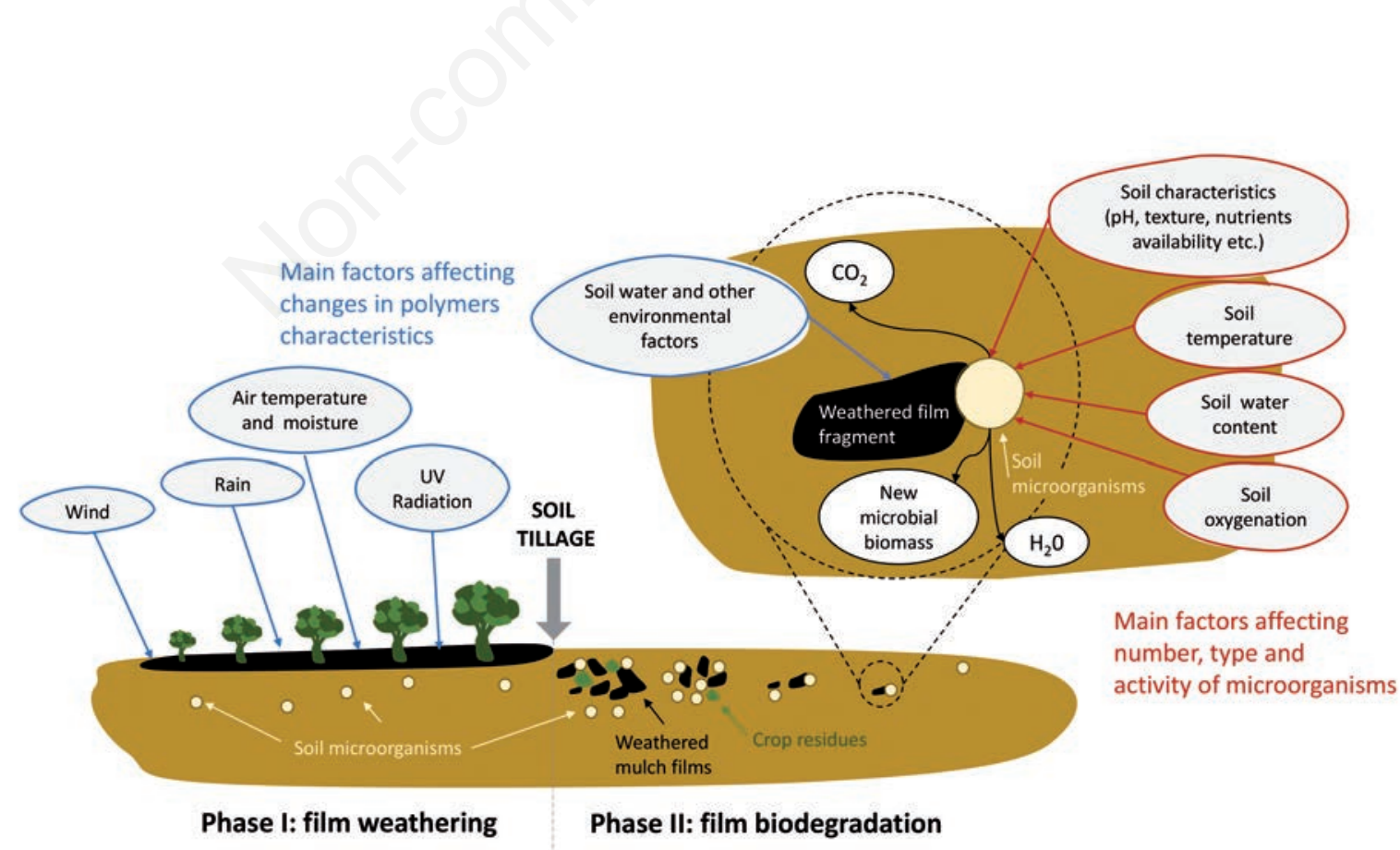

Figure 1. Abiotic and biotic degradation phases of mulch films during and after a cropping cycle. 


\section{Methods for the estimation of film biodegradation in soil}

Currently, there are different international standards for estimating the biodegradation of plastics in soil which the American Society provides for Testing and Materials (ASTM international, 2012), the International Organization for Standardization (ISO 17556, 2012), and the European Committee for Standardization (EN 17033, 2018). These standards each measure the evolved $\mathrm{CO}_{2}$ as a function of time of exposure, they are each performed with soil at a room temperature of $20-28 \pm 2^{\circ} \mathrm{C}$, and they each provide validation criteria (i.e., $\geq 90 \%$ conversion of tested material carbon into $\mathrm{CO}_{2}$ within 2 years in absolute terms or relative to a positive control such as microcrystalline cellulose). In addition, there are national standards that are comparable to the international ones, such as the Japanese standard JIS K 6955 (2017) (a modified version of ISO 17556, 2012) or the Italian standard UNI 11462 (2012). Furthermore, a new standard (ISO 23517, 2021) has been recently published, and similarly to EN 17033 (2018), it specifically addresses the biodegradation of mulch films for use in agriculture and horticulture, including evaluation of their ecotoxicity and control of constituents.

International standards have been criticised because they consider the release of $\mathrm{CO}_{2}$ as a unique proof that microorganisms consume the polymer, given that the polymer is the only carbon source. However, it is possible that the evolved $\mathrm{CO}_{2}$ could also derive from the breakdown of additives rather than actual polymer biodegradation (Lucas et al., 2008). However, these additives typically represent only a small portion of the commercial blend, and evolved $\mathrm{CO}_{2}$ should correspond to a very close estimation of mulch film biodegradation. Indeed, recent studies using ${ }^{13} \mathrm{C}$ labelling proved the biodegradability of PBAT (one of the most used polymers in manufacturing mulch films labelled as biodegradable in soil), showing that each monomer derived from it was used by soil microorganisms (Zumstein et al., 2018).

Besides national and international standards, other studies have used other methodologies to estimate the biodegradation of plastics in soil. These methods mainly include visual analysis, mass loss, and spectroscopy often used concomitantly and sometimes partially or totally following the standards mentioned above. For example, Apinya et al. (2015) and Vanharova et al. (2017) measured the $\mathrm{CO}_{2}$ evolved from biodegradable plastic samples based on international standards (ISO 17556, 2012 and ASTM international, 2012, respectively) together with measuring film mass loss and conducting spectroscopy and electron microscopy observations.

In this review, the estimation of film biodegradation with visual analysis, mass loss, and spectroscopy is defined as 'indirect methods'. In contrast, 'direct methods' include the estimation of biodegradation by measuring the evolved $\mathrm{CO}_{2}$ needed to confirm the biodegradability of mulch films or of the polymers that compose them.

\section{Aims and scope of this review}

This review aims at providing an overview of all the methods (i.e., direct and indirect) that various authors have used to estimate the biodegradation performances of biodegradable plastics in soil. It also provides a critical discussion of the advantages and limitations of each method used by the authors over the years. Finally, it gives suggestions on using the techniques currently available in different stages of research or for different purposes.

To achieve these aims, the literature from the last 30 years was systematically analysed to identify the methods used to estimate the biodegradation performances of potentially biodegradable mulch films.
This review will focus only on biodegradation in soil under field conditions or under laboratory conditions, which here is understood as a 'controlled simulation of open-field conditions' (SAPEA, 2020). Other environments or conditions of biodegradation (e.g., water or anaerobic landfills) are beyond the scope of this review. For an overview of methodological aspects of plastic degradation in aerobic composting and anaerobic digestion, refer to the recent reviews authored by Ruggero et al. (2019) and Quecholac-Piña et al. (2020).

\section{Materials and methods}

\section{Search criteria}

The articles were searched for in the Web of Science (https://webofknowledge.com/) in October 2020 using the 'advanced search mode' with the following search string: $T S=$ ((bioplastic OR polyesters) AND (CO2 OR decomposition OR biodegradation $O R$ respiration) $A N D$ soil)) which returned a total of 322 papers. Only papers explicitly dealing with biodegradable plastic degradation carried out in soil were selected and included in this review. A large part of the 322 papers was discarded because they explicitly reported elements unrelated to soil or only covered industrial production processes. Some papers that considered different environments besides soil were included, but the results were limited to results obtained from soil incubation or burial. Conversely, papers dealing exclusively with the biodegradation of polymers carried out in composting, aquatic, or anaerobic environments were not included. The total number of papers considered eligible and thus included in this review was 80 .

\section{Systematic literature review and estimation of polymer degradation}

After the selection, each paper was systematically analysed in order to extract information on soil characteristics used in the experiments, types of polymers analysed, and methods used to estimate their biodegradation in soil. Since papers often reported more than one polymer (either in pure form or as a blend), the database was set to match each polymer analysed to one research finding. For example, Hoshino et al. (2001) analysed PLA, PBS, and PBSA within the same paper, and that corresponded to three findings. For this reason, the total number of findings exceeds the total number of papers included. This review was limited to PLA, PBS, PBSA, and PBAT for pure polymers because these are among the most common polymers used to manufacture agricultural mulch films (Brodhagen et al., 2015). The most frequent commercial blends that emerged from the systematic review of the final 80 papers were Ecoflex (BASF) and Mater-Bi (Novamont), with 12 and 14 findings, respectively. Although Ecoflex was considered equal to PBAT and is therefore not separated from the others, Mater-Bi is reported separately in the Results section because it substantially differs from the others as it is a blend of mainly PBAT and thermoplastic starch.

Subsequently, using the reported lengths of the experiments and the estimated percentages of degradation for each polymer (using both indirect and direct methods), we predicted the number of days to reach $50 \%$ and $90 \%$ biodegradation and the percentage biodegradation after 6 months, assuming a linear relationship between time and degree of reported biodegradation. 


\section{Results and discussion}

\section{Main general experimental aspects emerging from the included papers}

The number of studies published over the last 30 years on the degradation of biodegradable polymers in soil showed a low but increasing trend, with an average publication rate of about 3.5 papers per year (Figure 2). Of the 80 selected studies, 58 (72\%) were carried out under laboratory conditions, whereas $9(11 \%)$ used a combined approach with laboratory and open-field analysis (e.g., Feuilloley et al., 2005; Moreno et al., 2017).
Not all authors included information on the origin or location of the soil used; however, most of the studies that reported this information were from Japan $(n=10)$ followed by the United States $(n=8)$ and Italy, France, and Spain ( $n=5$ for each of them). Most experiments $(n=52)$ used a 'not altered' soil, whereas, in 25 experiments, the soil was 'manipulated', for example, by Apinya et al. (2015), which used a forest soil mixed with mature compost from yard waste at a ratio of 25:1. Five papers used a 'commercial' soil (e.g., Puchalski et al., 2018). Authors generally reported basic information on the soil used in their experiments, of which the most frequent were $\mathrm{pH}$, carbon content, nitrogen content, and soil texture (Figure 3). In 32 papers, the substrate used was described merely as 'soil', and no other information was included.

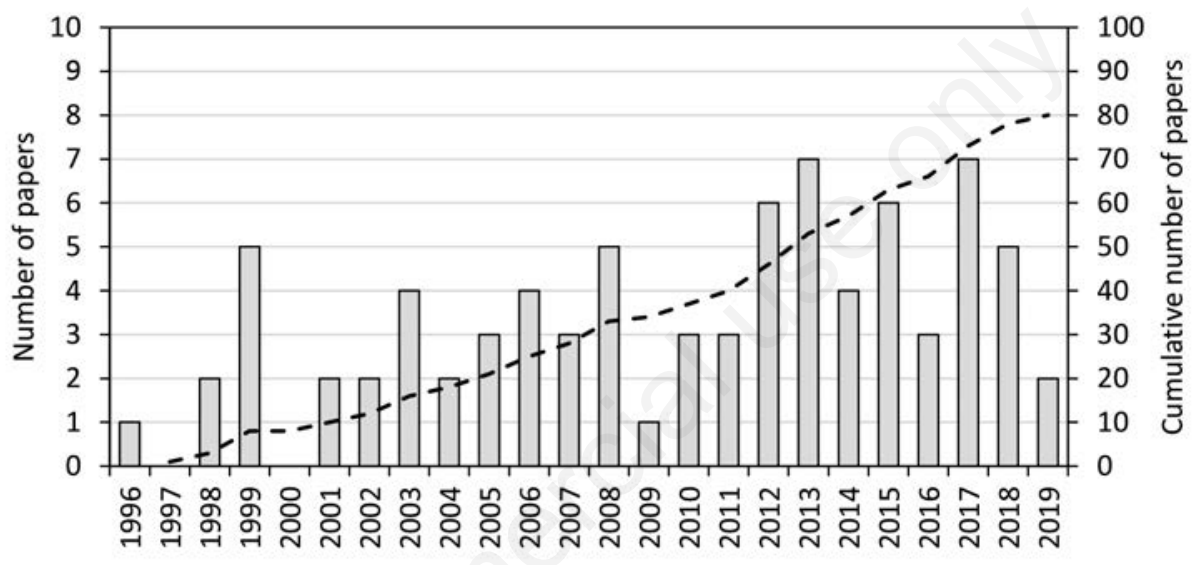

Figure 2. Trends and distribution of the 80 selected papers. The dashed line represents cumulative number of selected papers.

Figure 3. Main soil characteristics reported in the $\mathbf{8 0}$ selected papers. Studies that did not report any information regarding soil characteristics are indicated by the light grey bar. 
As expected, the materials that were most frequently studied were commercial films (i.e., mulch films already available on the market) or experimental blends (e.g., experimental spunbonded polylactic acid fabric) (e.g., Cowan et al., 2013). Again, PLA was the most frequently studied pure polymer, while the least frequently studied polymer was PBAT, which was included in experiments as a pure polymer only in 6 papers (Figure 4 ).

\section{Reported degradation rates of the studied polymers}

The stated biodegradation rates of biodegradable plastics or polymers in this review are derived from different soils, different soil:polymer ratios (in the case of laboratory incubations), differences in investigated materials, and often estimated using indirect methods only. For these reasons, the results reported in this review are not to be taken as a precise estimation of the biodegradation of each polymer. Instead, this review provides the range of reported biodegradation for a certain polymer either under laboratory or field conditions, using direct and indirect methods. It is not surprising that each of the analysed polymers showed marked differences in biodegradation rates with a vast range of values around the estimated mean. Furthermore, differences between estimated means were appreciable also within the same polymer when studies were carried out under laboratory or field conditions (Figure 5).

Experiments carried out under laboratory-controlled conditions resulted in faster rates of degradation of the same polymer compared to the experiments carried out under open-field conditions, except for PBAT, which seems on average to be degraded 4 times as fast under field conditions (Table 1). This polymer was investigated in 15 experiments, of which 7 were carried out under open-field conditions. In 2 of these 7 experiments, the reported degradation was estimated only by visual methodologies, which could have led to gross overestimation. Since PBAT a is polyester with ester groups within its partially aromatic chain, its biodegradation is supposed to be relatively low (Moore-Kucera et al., 2014). Indeed, another study carried out under laboratory conditions showed that pure PBAT polyester underwent minimal degradation as measured by $\mathrm{CO}_{2}$ evolution after 100 days of incubation in real soil at $25^{\circ} \mathrm{C}$ (Šerá et al., 2016). On the other hand, a degradation of about $10 \%$ was detected by Zumstein et al. (2018) after about 40 days, although in this case, the experiment was intentionally interrupted to allow other visual analyses. Indeed, if the two studies which likely overestimated the biodegradation of PBAT are

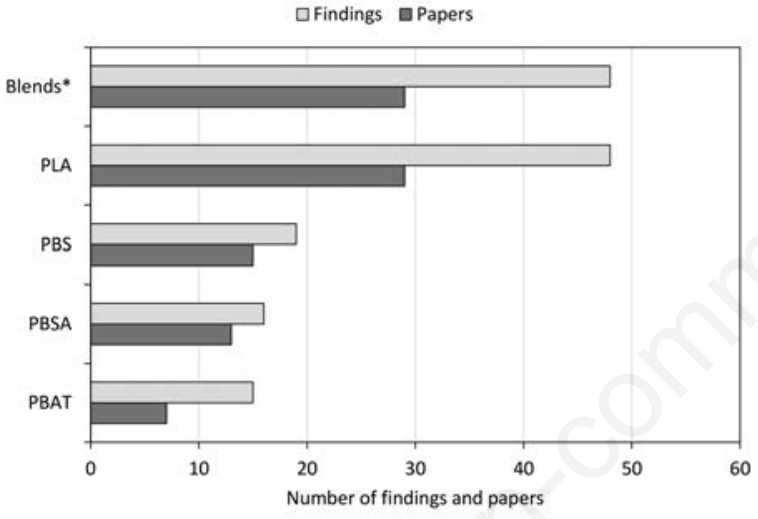

Figure 4. Number of findings and papers for the types of polyesters reported in the 80 selected papers. *'Blends' includes different commercial and experimental biodegradable mulch films.

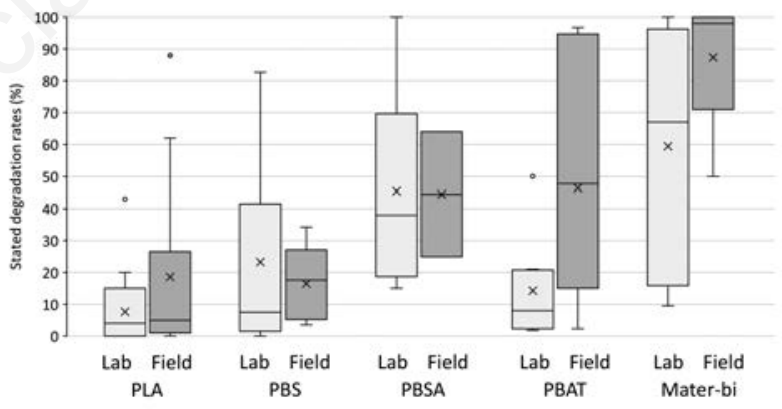

Figure 5. Reported biodegradation with direct and indirect methods for each studied polymer in laboratory (lab) and field conditions.

Table 1. Stated percentages of biodegradation (mean \pm SD) for each polymer analysed in soil, and linear forecast of days required to reach $50 \%$ and $90 \%$ biodegradation and estimated percentage of biodegradation after 6 months.

\begin{tabular}{|c|c|c|c|c|c|c|}
\hline \multirow[t]{2}{*}{ Polymer } & \multirow{2}{*}{ Condition } & \multirow{2}{*}{ Degradation (\%) } & \multirow[t]{2}{*}{ Mean length (days) } & \multicolumn{3}{|c|}{ Estimation of degradation } \\
\hline & & & & Days to $50 \%$ & Days to $90 \%$ & $\%$ after 6 months \\
\hline \multirow[t]{2}{*}{ PLA } & Lab & $0.08 \pm 0.11$ & 126 & 825 & 1485 & $11 \%$ \\
\hline & Field & $0.19 \pm 0.27$ & 392 & 1055 & 1900 & $9 \%$ \\
\hline \multirow[t]{2}{*}{ PBS } & Lab & $0.23 \pm 0.29$ & 114 & 244 & 440 & $37 \%$ \\
\hline & Field & $0.16 \pm 0.12$ & 163 & 495 & 890 & $18 \%$ \\
\hline \multirow[t]{2}{*}{ PBSA } & Lab & $0.45 \pm 0.30$ & 124 & 137 & 247 & $66 \%$ \\
\hline & Field & $0.44 \pm 0.28$ & 209 & 235 & 422 & $38 \%$ \\
\hline \multirow[t]{2}{*}{ PBAT } & Lab & $0.14 \pm 0.16$ & 197 & 690 & 1241 & $13 \%$ \\
\hline & Field & $0.46 \pm 0.38$ & 138 & 148 & 267 & $61 \%$ \\
\hline \multirow[t]{2}{*}{ Mater-Bi } & Lab & $0.59 \pm 0.40$ & 163 & 137 & 247 & $65 \%$ \\
\hline & Field & $0.87 \pm 0.20$ & 253 & 145 & 261 & $62 \%$ \\
\hline
\end{tabular}


removed, the days needed to reach $50 \%$ degradation would double (i.e., from 148 to 312 days), which, however, seems to be again a too small time window. Thus, if the main aim is to quantify the biodegradation rates of the mulch films, visual estimation in the open field, if not coupled with other methods, could lead to remarkable biases. When using indirect methods such as the remaining surface area to quantify the biodegradation rates of the mulch films, it is necessary to acknowledge that these methods do not prove biodegradation (Zumstein et al., 2019). For example, an overestimation might occur if film fragments are not retrieved from the field (e.g., lost through the mesh bags holes), while an underestimation might occur when the film biodegradation process changes film thickness leaving no detectable changes in the surface area.

The results obtained from the analysed papers suggest that, on average, PLA had the slowest biodegradation rate (Table 1). This finding appears to be aligned with the literature as studies confirm that PLA-degrading microorganisms are not widely distributed in the soil, and thus PLA is expected to degrade slowly in natural soil (Tokiwa et al., 2009). Furthermore, slow degradation of PLA is reported, for example, by Apinya et al. (2015) under laboratory conditions and by Cowan et al. (2013) under open-field conditions. For these reasons, results like the ones reported in one paper, which reported a PLA weight loss of $88 \%$ after 2 years of soil burial, appear to be at least questionable.

Although it has been reported that the microorganisms that degrade PBS are widely distributed (Tokiwa et al., 2009), from the estimation presented in Table 1, it seems that PBSA can be degraded faster than PBS on average. Indeed, rapid degradation of PBSA in soil has been reported, for example, by Kitamoto et al. (2011), who observed a degradation rate of more than $80 \%$ after 6 weeks, or by Yamamoto-Tamura et al. (2015), who reported a PBSA degradation rate of close to $44 \%$ in 28 days.

What emerges clearly is that the published experiments show very diverse and sometimes conflicting results to date. This is because different biotic and abiotic factors influence the biodegradation of films and/or the polymers that compose them. Such factors include the process of film manufacture, the ratio of the different polymers within the final commercial product, the weathering process (i.e., the action sun, rain, wind, and temperature), and all of the biotic components of soil, including enzyme activities of the fungi and bacteria naturally occurring in real soil environments (Figure 1). This high context-dependency coupled with the lack of a shared methodology for estimating biodegradation of plastic in the soil likely results in over- or underestimations of degradation rates. The consequence is that the results obtained from different studies are seldom comparable. However, these estimations, albeit imprecise, represent the currently available data. Furthermore, these data derive from different and widely used methodologies that can be grouped into direct $\left(\mathrm{CO}_{2}\right.$ evolution) and indirect methods (visual analysis, mass loss measurements, and spectroscopy). An overview of such methodologies is presented and critically discussed below.

\section{Methods used for the estimation of plastic biodegradation}

The most frequent methodologies used to estimate biodegradation were visual analysis and mass loss, followed by spectroscopy and the release of $\mathrm{CO}_{2}$ (Figure 6). Ruggero et al. (2019) recently reviewed the methods used to determine biodegradable plastic degradation under aerobic composting and digestion and reported a more balanced distribution between the same four categories of methodologies compared to the one illustrated here. However, similarly to the results reported by Ruggero et al. (2019), the studies selected here generally used a combination of two or more
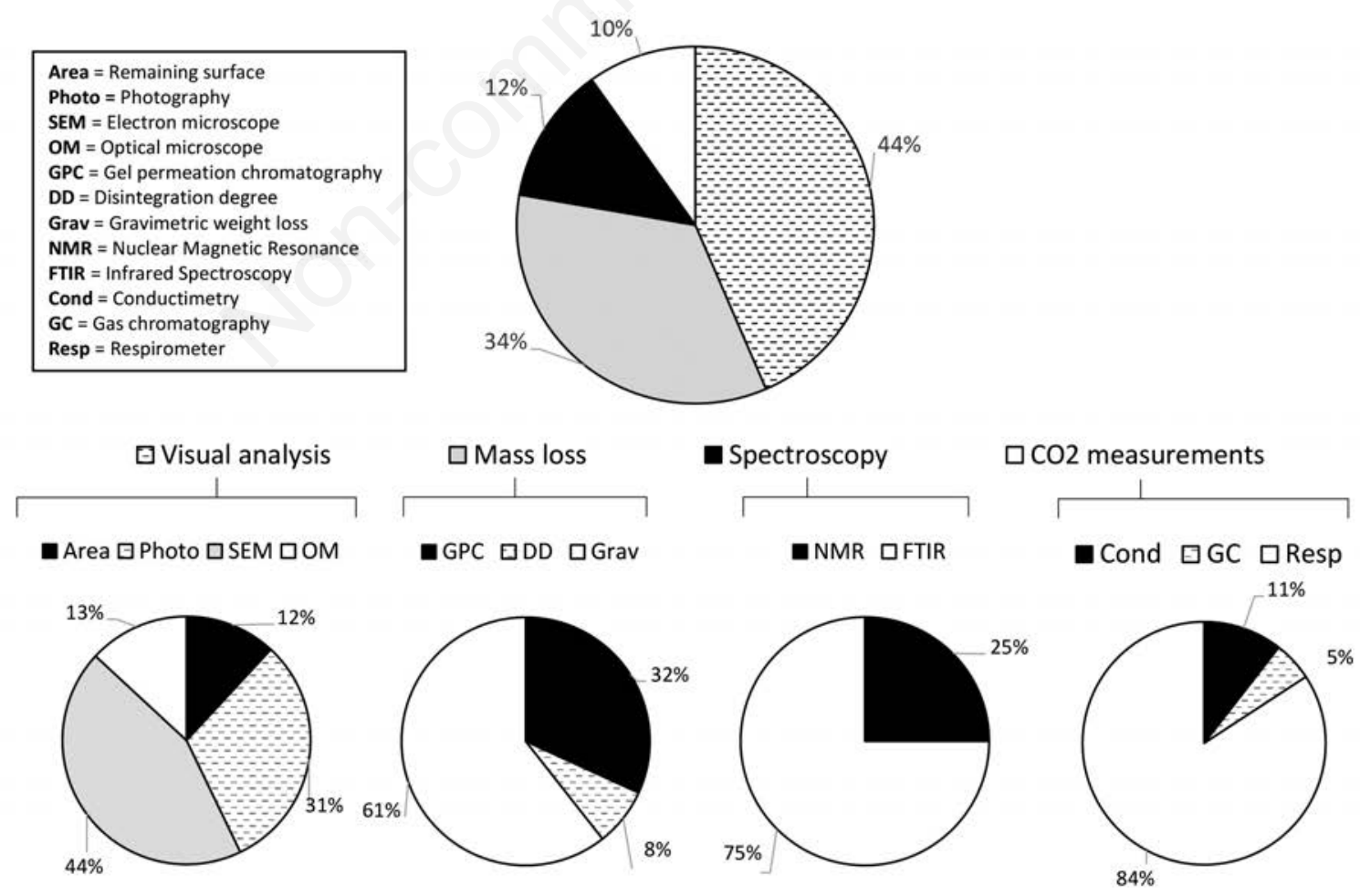

Figure 6. Details of reported methodologies used to estimate plastic biodegradation in soil. 
methodological approaches. In the following section, the methodologies developed and used in the selected papers are presented and discussed.

\section{Visual analysis}

Visual analysis methods, used in 71 out of 80 papers are utilised as a 'proxy' for evaluating the biodegradation of plastics. Visual analysis can consider various criteria, including physical erosion (e.g., cracks, holes, tunnels), fragmentation, remaining surface area, or signs of microbial colonisation.

Photography was commonly used to show signs of abiotic degradation through weathering in open field trials (e.g., Briassoulis, 2007; Li et al., 2014) and, to a lesser extent, also in laboratory incubation experiments (e.g., Someya et al., 2007). Yamamoto-Tamura et al. (2015) used photographic analysis after the burial of $2 \times 2 \mathrm{~cm}$ pieces of PBSA film in a laboratory incubation experiment and monitored the remaining area of film over time. Visual analysis has the advantage of showing a clear temporal path and might be suited for the estimation of the residual area over time. Visual analysis could be easily coupled with film mass loss or $\mathrm{CO}_{2}$ evolution analysis if adequately designed. The estimation of the area of the film remaining after a certain period was also used under open-field conditions by visually assigning scaled values to the degree of plastic film deterioration during the cropgrowing season (Miles et al., 2012). For example, the estimation of remaining areas was used in open-field trials by Cowan et al., 2013 via photography and subsequent use of image analysis software which can transform the image into binary (i.e., only white and black pixels). Percentage of soil cover is extensively used in other disciplines such as vegetation surveys and it might be used to evaluate the effect of film weathering in open field but it should never be used as an estimate of the biodegradation of mulch films.

Scanning electron microscopy (SEM), one of the most frequently used visual methods, acquires an image of the object surface by using an electron beam. For example, in one study, cracks on the film surface were found near bacterial filament traces, suggesting the involvement of bacterial extracellular enzymes that degrade the film (Šerá et al., 2016). On the other hand, Kamiya et al. (2007) observed hollows along fungal hyphae on the surface of biodegradable plastics, while holes and pits (which indicate bacterial decomposition of the biodegradable plastics) were not found, suggesting that soil fungi were the main contributors to the biodegradation process.

Although visual estimation does not give the ultimate proof of polymer biodegradation, this method can be a valid help in estimating biodegradation rates and could act as a 'control' to be associated with open-field trials that use remaining visual area or in incubation experiments that use polymers in powder form. For example, Brodhagen et al. (2015) suggested that visible deterioration of the biodegradable plastic surface may be caused by factors such as acid weathering rather than enzymatic decomposition. Zumstein et al. (2018) used SEM to show signs of microbial colonization on different types of ${ }^{13} \mathrm{C}$-labelled PBAT also using isotope-selective nanoscale secondary ion mass spectrometry (NanoSIMS) coupled with cavity ringdown spectroscopy to demonstrate PBAT biodegradability.

Indeed, even if the shape or surface of polymer changes, that is not sufficient to prove its biodegradability. Confirmation of whether microorganisms mineralise the polymer is necessary as a proof of its ultimate biodegradation.

\section{Mass loss}

Mass loss was the second most frequently used method for assessing the biodegradation of polymers (Figure 6). Among these methods, gravimetric weight loss was the most frequently used probably because it is the most 'immediate and easy' in quantifying changes in plastic films over time. This method generally consisted of washing samples in distilled or 'MilliQ' water, drying to constant mass, and final weighing. This technique has the advantage of being able to be performed both under open field conditions (e.g., Wang et al., 2015) and laboratory conditions (e.g., Barragán et al., 2016), but there is no guarantee that all the fragments (especially fragments not visible to the naked eye) will be included in the analysis because they can be lost during the sample cleaning process.

Gel permeation chromatography (GPC) is an analytical technique that separates dissolved macromolecules by size based on their elution from columns filled with a porous gel. Using GPC makes it possible to characterize different molecules, including natural or synthetic polymers. The generated information on shifts in the polymer molecular weight distribution toward smaller masses is generally considered an indirect indicator of biodegradation (Monáčsnková et al., 2017; Ruggero et al., 2019). GPC was used in 21 out of 80 papers, always coupled with other techniques such as SEM and gas chromatography (Šerá et al., 2016).

The disintegration degree, i.e., percentage of particles retained on a 2-mm mesh sieve, dried to constant mass, and weighed after 90 days in a laboratory-scale test (Ruggero et al., 2019), was seldom used (Figure 6).

Attempting to precisely measure the biodegradation of plastic films using only mass loss measurement is not acceptable from a scientific point of view because it would likely lead to incomplete, wrong, or even harmful conclusions (Zumstein et al., 2019). Nevertheless, most studies used mass loss; however, this was always coupled with other methods but rarely with direct methods (e.g., Apinya et al., 2015).

\section{Spectroscopy}

Some of the selected papers (12/80) also used spectroscopy to assess the biodegradation of polymers, although it was always used in combination with other techniques such as respirometers $\left(\mathrm{CO}_{2}\right.$ evolution) and visual analysis (e.g., Feuilloley et al., 2005; Vanharova et al., 2017). Spectroscopy detects changes in the polymer spectrum after polymer abiotic or biotic degradation. Although different types of spectroscopic analysis are available, most of the selected papers used Fourier-transform infrared spectroscopy (FTIR). For example, Barragán et al. (2016) used FTIR to detect changes in absorbance at specific wavenumbers in commercial and experimental mulch films. They reported a decrease in the intrinsic peak of the ester bond (1640-1840 $\left.\mathrm{cm}^{-1}\right)$ and a change in the absorption peak specific to the material and suggested that decreases in the peak absorbances were attributable to the microbial biodegradation of the material. Some of the papers $(6 / 80)$ also used nuclear magnetic resonance (NMR), which can detect functional groups and determine monomer ratios for the analysed polymers (Ruggero et al., 2019). For example, Rychter et al. (2010) used NMR on PBAT rods incubated in sandy soil but detected no changes between the ratios of terephthalate and adipate, suggesting no compositional preferences in the biodegradation process. The NMR, in that case, was coupled with size-exclusion chromatography and weight loss, which however showed limited signs of biodegradation after 22 months of incubation. However, it is well-known that biodegradation is a surface process and using 
PBAT rods likely biased the results. Conversely, Sintim et al. (2020) indicated that the ratio of PLA in PLA:PHA manufactured mulch significantly increased after burial in soil for 3 years at two different locations. In these cases, the spectroscopic analyses were useful for evaluating biodegradable plastics' deterioration in soils. However, further studies are needed to clarify whether these spectroscopic alterations arise from abiotic or biotic factors or both factors in soils.

\section{$\mathrm{CO}_{2}$ evolution}

According to the international standards (ISO 17556:2012, ASTM D5998 and EN 17033), biodegradation of plastic can be assessed by measuring the $\mathrm{CO}_{2}$ that evolves from the metabolic activities of soil microorganisms, when the tested material is the sole source of carbon present in the soil. This has been discussed in many reviews, and it is generally agreed that this method gives a precise measure of the percentage of mineralised carbon under laboratory-controlled conditions (Kyrikou and Briassoulis, 2007; Kasirajan and Ngouajio, 2012; Li et al., 2014; Brodhagen et al., 2015; Briassoulis and Degli Innocenti, 2017; Bandopadhyay et al., 2018). However, there are some shortcomings with $\mathrm{CO}_{2}$ measurements, such as failing to define the fate of additives, leaving room for risk of potential soil ecotoxicity (Lucas et al., 2008; Zumstein et al., 2019). This aspect is expected to be overcome by including the soil ecotoxicity tests in the new ISO 23517:2021 as well as in EN 17033 standard.

Most of the studies that estimated the biodegradation of polyesters by measuring $\mathrm{CO}_{2}$ evolution from the tested material followed ISO and/or ASTM standards and most used respirometers (Table 2). Other methodologies used for $\mathrm{CO}_{2}$ estimation included conductimetry (e.g., Thompson et al., 2019) and gas chromatogra-

Table 2. Papers measuring degradation of polyesters by $\mathrm{CO}_{2}$ evolution, with the main experimental settings and the international standard adopted.

\begin{tabular}{|c|c|c|c|c|c|c|}
\hline Authors & Soil type & Standard used & $\begin{array}{l}\text { Tested } \\
\text { material/soil } \\
\text { weight }(\mathrm{g} / \mathrm{g})\end{array}$ & $\begin{array}{l}\text { Temp } \\
\left({ }^{\circ} \mathrm{C}\right)\end{array}$ & $\begin{array}{l}\text { Water } \\
(\% \mathrm{Vol})\end{array}$ & $\begin{array}{l}\text { Length of } \\
\text { experiment } \\
\text { (days) }\end{array}$ \\
\hline Abe et al., 2010 & $\begin{array}{l}\text { Manipulated (Commercial } \\
\text { andosol, Alles G inoculum, } \\
\text { commercial compost, sawdust) }\end{array}$ & - & $1.54 / 5.5$ & - & 60 & 14 \\
\hline Apinya et al., 2015 & $\begin{array}{l}\text { Manipulated (forest soil mixed } \\
\text { with mature compost from } \\
\text { yard waste) }\end{array}$ & ASTM D5988-12 (2003) & $0.72 / 200$ & $30 \pm 2$ & 45 & 60 \\
\hline Ardisson et al., 2014 & $\begin{array}{l}\text { Manipulated (addition of compost } \\
+ \text { other elements) }\end{array}$ & ISO 17556 (2012) & $10 / 800$ & $28 \pm 2$ & - & 318 \\
\hline Barragán et al., 2012 & Natural & ISO 17556 (AENOR, 2005) & $0.5 / 200$ & $25 \pm 2$ & - & 90 \\
\hline Gómez and Michel, 2013 & $\begin{array}{l}\text { Manipulated (mixture } \\
\text { of } 43 \% \text { certified organic } \\
\text { topsoil, } 43 \% \text { no-till farm soil } \\
\text { and } 14 \% \text { sand, ammonium } \\
\text { phosphate) }\end{array}$ & ASTM D5988-03 & $1^{\dagger} / 300$ & $20 \pm 2$ & 60 & 660 \\
\hline Ho and Pometto, 1999 & $\begin{array}{l}\text { Manipulated (soil mixture } \\
\text { of potting soil, manure soil, } \\
\text { sand [1:1:1 (w/w)]) }\end{array}$ & - & $1.5 / 200$ & 28 & - & 182 \\
\hline Jeszeová et al., 2018 & Manipulated (soil and perlite) & $\begin{array}{l}\text { ASTM D5988-12 and } \\
\text { STN 17556-2012 }\end{array}$ & $0.45 / 200$ & 20 & - & 365 \\
\hline Mccarthy et al., 1999 & Natural & - & - & 37 & - & 45 \\
\hline Mosnáčková et al., 2017 & $\begin{array}{l}\text { Manipulated } \\
\text { (soil and perlite) }\end{array}$ & $\begin{array}{l}\text { ASTM D5988-12 and } \\
\text { STN 17556-2012 }\end{array}$ & $-/ 200$ & 20 & - & 375 \\
\hline Palsikowski et al., 2018 & $\begin{array}{l}\text { Natural (collected from } \\
\text { different areas and mixed) }\end{array}$ & ASTM D5988-12 & $-/ 200$ & 28 & 47 & 120 \\
\hline Ratto et al., 1999 & $\begin{array}{l}\text { Manipulated (mix of potting soil, } \\
\text { sand, and composted manure) }\end{array}$ & - & $0.45-0.48 / 50$ & 30 & $60 \pm 5$ & 368 \\
\hline Šerá et al., 2016 & Manipulated (soil, perlite) & - & $0.1 \mathrm{~g} / 10 \mathrm{~g}$ & 25 & - & 100 \\
\hline Solaro et al., 1998 & $\begin{array}{l}\text { Manipulated }(15: 10 \text { mixture of forest } \\
\text { soil and agricultural soil, } \\
\left.\text { addition of }\left(\mathrm{NH}_{4}\right)_{2} \mathrm{HPO}_{4}\right)\end{array}$ & - & $0.3 \mathrm{~g}^{\dagger} / 10-12.5$ & Room temp. & - & $82-125$ \\
\hline Thompson et al., 2019 & $\begin{array}{l}\text { Manipulated (Biodegradation } \\
\text { stimulants, urea, sucrose, nitrogen) }\end{array}$ & ISO 17556 & $-/ 150 \mathrm{~g}$ & 23 & 60 & 112 \\
\hline Touchaleaume et al., 2016 & Natural & ASTM D5988-96 & $0.002^{\dagger} / 1$ & 28 & - & 750 \\
\hline Vanharova et al., 2017 & $\begin{array}{l}\text { Manipulated (clay soil, commercial } \\
\text { garden compost (1:5) and } 100 \mathrm{~mL} \\
\text { of liquid medium) }\end{array}$ & ISO 17556:2012 & $1 / 500^{\S}$ & - & - & 70 \\
\hline
\end{tabular}

tgrams of carbon instead of grams of material; §volume in $\mathrm{cm}^{3}$ instead of weight in grams. 
phy (e.g., Šerá et al., 2016). Regardless of the adopted method, the main limitation of $\mathrm{CO}_{2}$ measurement for estimating biodegradation rates is that it can be practically carried out only under laboratorycontrolled conditions. Techniques for the measurement of soil $\mathrm{CO}_{2}$ emissions typically used under open-field conditions, such as portable infrared gas analysers (e.g., Francioni et al., 2019), are not suited because they are likely, not able to detect and separate soil heterotrophic respiration and the $\mathrm{CO}_{2}$ evolved from the biodegradable plastic films, which is expected to be very small.

Generally, what emerges from the papers analysed is great attention to the chemical composition of the polymers as opposed to a scarce (if present at all) attention to the characteristics of the soil (Figure 3). Soil physiochemical characteristics play a key role in the biodegradation of polymers as they significantly influence the microbial activity and, thus, the amount of $\mathrm{CO}_{2}$ evolved from microbial assimilation of biodegradable plastic. Moreover, the ratio of film and soil used in the incubation experiments was sometimes not reported clearly. Making this information easy to note would be desirable because it would make the experiments easier to replicate and might help simulate the presence of plastic film in real soil at the end of each cropping cycle when it should be incorporated into the soil through tillage.

\section{Implications and future prospects}

This review analysed the methods used to estimate the degradation of biodegradable plastics in the soil environment. Generally, two or more methods have been used simultaneously within the same study. However, the most frequently used methods were indirect (i.e., visual analysis and mass loss, followed by spectroscopy), leaving the direct ones (i.e., the release of $\mathrm{CO}_{2}$ ) as the least used, despite being the only ones capable of proving the biodegradation of the polymer. The reported results appear to be very dispersed even with the same polymer and under the same conditions (i.e., laboratory-controlled or open-field). From this perspective, there is a need to standardise the methodologies either under laboratory or field conditions to make studies as comparable and replicable as possible.

Many papers analysing biodegradable plastics in soil are 'chemical-engineering oriented' and investigate film physicochemical characteristics, including crystallinity, elongation until breakage, and other such parameters. These types of studies represented most of the papers that were extracted but not included in this review. Nevertheless, this field of research remains of utmost importance because of the continuous improvement of commercial products. However, what often emerges in these types of studies and in some of the studies included in this current review is that soil characteristics (Figure 3) are of little importance. Agricultural soil is where biodegradable mulch films are meant to be buried and, hopefully, ultimately biodegraded by microorganisms. Thus, much more attention is required when dealing with biodegradable plastics to be used in agriculture because soils are profoundly heterogeneous, and the 'soil environment' must not be considered a 'standard environment'. Therefore, future studies must include standard environmental parameters (e.g., room temperature and soil:polymer ratio for laboratory experiments and meteorological conditions for field trials), but they cannot disregard an accurate description of the soil used.

Almost none of the analysed papers clearly presented an agronomic perspective that should be considered, especially in open field trials. Future studies should not be limited only to comparing the performance of standard mulches with that of biodegradable mulches in crop yields and quality. However, they should also investigate the effects of different agronomic practices, such as different timing, frequency, or depths of tillage used to incorporate plastic into the soil. Although this might be an essential aspect of research for crop scientists, it was never included in any of the 80 papers analysed in this review.

There are objective difficulties in using direct methods for estimating biodegradation under open field conditions. In this case, the use of indirect methods for the analysis of biodegradation of mulch films might be useful but must be considered only as indicators of potential biodegradation. For this reason, future studies using indirect methods should use mulch film whose biodegradability in soil environment has already been demonstrated in previous studies. However, a new methodology that combines polymer extraction and NMR analysis has been recently proposed to quantitively assess the biodegradation rates of the polymer under open field conditions over time (Nelson et al., 2020).

Soil biodegradable mulch films are available on the market, but farmers still seldom use them (Malinconico, 2017). A great help in moving beyond the use of non-biodegradable polyethylene mulch films could be given by policy tools such as agri-environmental measures or payment for ecosystem services (Scaringelli et al. 2016). If properly managed, these tools can directly involve all stakeholders (i.e., farmers, policymakers, and researchers) in collaborative research approaches, resulting in efficient incentivebased systems (Toderi et al., 2017). However, to create such tools, there is first the need to show to farmers and policymakers that certain mulch films can be biodegraded in the soil. It must be pointed out that the confirmation of the biodegradability of mulch films through direct methods (i.e., $\mathrm{CO}_{2}$ evolution) remains necessary from the scientific point of view, but this can be coupled with indirect methods that are more suitable for facilitating dialogue with policymakers, farmers, and other stakeholders.

\section{References}

Abe M, Kobayashi K, Honma N, Nakasaki K, 2010. Microbial degradation of poly(butylene succinate) by Fusarium solani in soil environments. Polym. Degrad. Stab. 95:138-43.

Apinya T, Sombatsompop N, Prapagdee B, 2015. Selection of a Pseudonocardia sp. RM423 that accelerates the biodegradation of poly(lactic) acid in submerged cultures and in soil microcosms. Int. Biodeterior. Biodegrad. 99:23-30.

Ardisson GB, Tosin M, Barbale M, Degli-Innocenti F, 2014. Biodegradation of plastics in soil and effects on nitrification activity. A laboratory approach. Front. Microbiol. 5:1-7.

ASTM International, 2012. standard test method for determining aerobic biodegradation of plastic materials in soil, D5988-12. ASTM International, West Conshohocken, USA.

Bandopadhyay S, Martin-Closas L, Pelacho AM, DeBruyn JM, 2018. Biodegradable plastic mulch films: Impacts on soil microbial communities and ecosystem functions. Front. Microbiol. 9:1-7.

Barragán DH, Pelacho AM, Martin-Closas L, 2016. Degradation of agricultural biodegradable plastics in the soil under laboratory conditions. Soil Res. 54:216-24.

Barragán DH, Pelacho AM, Martín-Closas L, 2012. A respirometric test for assessing the biodegradability of mulch films in the soil. Acta Hortic. 938:369-76.

Briassoulis D, 2007. Analysis of the mechanical and degradation 
performances of optimised agricultural biodegradable films. Polym. Degrad. Stab. 92:1115-32.

Briassoulis D, Degli Innocenti F, 2017. Standards for Soil Biodegradable Plastics. In: Soil degradable bioplastics for a sustainable modern agriculture. Springer, Berlin, Heidelberg, pp 139-68.

Brodhagen M, Peyron M, Miles C, Inglis DA, 2015. Biodegradable plastic agricultural mulches and key features of microbial degradation. Appl. Microbiol. Biotechnol. 99:103956.

Cowan JS, Inglis DA, Miles CA, 2013. Deterioration of three potentially biodegradable plastic mulches before and after soil incorporation in a broccoli field production system in Northwestern Washington. Horttechnology 23:849-58.

EN 17033, 2018. Plastics-biodegradable mulch films for use in agriculture and horticulture-requirements and test methods. European Standard, European Committee for Standardization, Brussels, Belgium.

Feuilloley P, César G, Benguigui L, Grohens Y, Pillin I, Bewa H, Lefaux S, Jamal M, 2005. Degradation of polyethylene designed for agricultural purposes. J. Polym. Environ. 13:34955 .

Francioni M, D’Ottavio P, Lai R, Trozzo L, Budimir K, Foresi L, Kishimoto-Mo AW, Baldoni N, Allegrezza M, Tesei G, Toderi M, 2019. Seasonal soil respiration dynamics and carbon-stock variations in mountain permanent grasslands compared to arable lands. Agriculture 9:165.

Gorrasi G, Pantani R, 2018. Hydrolysis and biodegradation of poly(lactic acid). In: Di Lorenzo ML, Androsch R (Eds.), Synthesis, structure and properties of poly(lactic acid). Springer International Publishing, Cham, pp 119-51.

Gómez EF, Michel FC, 2013. Biodegradability of conventional and bio-based plastics and natural fiber composites during composting, anaerobic digestion and long-term soil incubation. Polym. Degrad. Stab. 98:2583-91.

Ho KLG, Pometto AL, 1999. Temperature effects on soil mineralization of polylactic acid plastic in laboratory respirometers. J. Environ. Polym. Degrad. 7:101-8.

Hoshino A, Sawada H, Yokota M, Tsuji M, Fukuda K, Kimura M, 2001. Influence of weather conditions and soil properties on degradation of biodegradable plastics in soil. Soil Sci. Plant Nutr. 47:35-43.

ISO 17556, 2012. Plastics - determination of the ultimate aerobic biodegradability of plastic materials in soil by measuring the oxygen demand in a respirometer or the amount of carbon dioxide evolved. International Organization for Standardization, Switzerland.

ISO 23517, 2021. Plastics - Soil biodegradable materials for mulch films for use in agriculture and horticulture - Requirements and test methods regarding biodegradation, ecotoxicity and control of constituents. International Organization for Standardization, Switzerland.

Jeszeová L, Puškárová A, Bučková M, Kraková L, Grivalský T, Danko M, Mosnáčková K, Chmela Š, Pangallo D, 2018. Microbial communities responsible for the degradation of poly(lactic acid)/poly(3-hydroxybutyrate) blend mulches in soil burial respirometric tests. World J. Microbiol. Biotechnol. 34:1-12.

Kamiya M, Asakawa S, Kimura M, 2007. Molecular analysis of fungal communities of biodegradable plastics in two Japanese soils. Soil Sci. Plant Nutr. 53:568-74.

Kasirajan S, Ngouajio M, 2012. Polyethylene and biodegradable mulches for agricultural applications: a review. Agron. Sustain.
Dev. 32:501-29.

Kitamoto HK, Shinozaki Y, Cao X hong, Morita T, Konishi M, Tago K, Kajiwara H, Koitabashi M, Yoshida S, Watanabe T, Sameshima-Yamashita Y, Nakajima-Kambe T, Tsushima S, 2011. Phyllosphere yeasts rapidly break down biodegradable plastics. AMB Express 1:1-11.

Kjeldsen A, Price M, Lilley C, Guzniczak E, Archer I, 2019. A review of standards for biodegradable plastics with support from. Ind. Biotechnol. Innov. Cent. IBioIC:33.

Kyrikou I, Briassoulis D, 2007. Biodegradation of agricultural plastic films: a critical review. J. Polym. Environ. 15:125-50.

Li C, Moore-Kucera J, Miles C, Leonas K, Lee J, Corbin A, Inglis D, 2014. Degradation of potentially biodegradable plastic mulch films at three diverse U.S. locations. Agroecol. Sustain. Food Syst. 38:861-89.

Lucas N, Bienaime C, Belloy C, Queneudec M, Silvestre F, NavaSaucedo JE, 2008. Polymer biodegradation: mechanisms and estimation techniques - a review. Chemosphere 73:429-42.

Malinconico M, 2017. Soil degradable bioplastics for a sustainable modern agriculture (M. Malinconico, Ed.). Springer Berlin Heidelberg, Berlin, Heidelberg.

Martín-Closas L, Costa J, Pelacho AM, 2017. Agronomic effects of biodegradable films on crop and field environment. pp 67-104 in Soil degradable bioplastics for a sustainable modern agriculture.

Mccarthy SP, Ranganthan A, Ma W, 1999. Advances in properties and biodegradability of co-continuous, immicisible, biodegradable, polymer blends. Macromol. Symp. 144:63-72.

Miles C, Wallace R, Wszelaki A, Martin J, Cowan J, Walters T, Inglis D, 2012. Deterioration of potentially biodegradable alternatives to black plastic mulch in three tomato production regions. HortScience 47:1270-7.

Moore-Kucera J, Cox SB, Peyron M, Bailes G, Kinloch K, Karich $\mathrm{K}$, Miles C, Inglis DA, Brodhagen M, 2014. Native soil fungi associated with compostable plastics in three contrasting agricultural settings. Appl. Microbiol. Biotechnol. 98:6467-85.

Moreno MM, González-Mora S, Villena J, Campos JA, Moreno C, 2017. Deterioration pattern of six biodegradable, potentially low-environmental impact mulches in field conditions. J. Environ. Manage. 200:490-501.

Mosnáčková K, Danko M, Šišková A, Falco LM, Janigová I, Chmela Š, Vanovčanová Z, Omaníková L, Chodák I, Mosnáček J, 2017. Complex study of the physical properties of a poly(lactic acid)/poly(3-hydroxybutyrate) blend and its carbon black composite during various outdoor and laboratory ageing conditions. RSC Adv. 7:47132-42.

Nelson TF, Remke SC, Kohler HPE, McNeill K, Sander M, 2019. Quantification of synthetic polyesters from biodegradable mulch films in soils. Environ. Sci. Technol. 54: 266-75.

Palsikowski PA, Kuchnier CN, Pinheiro IF, Morales AR, 2018. Biodegradation in soil of PLA/PBAT blends compatibilized with chain extender. J. Polym. Environ. 26:330-41.

Puchalski M, Szparaga G, Biela T, Gutowska A, Sztajnowski S, Krucińska I, 2018. Molecular and supramolecular changes in polybutylene succinate (PBS) and polybutylene succinate adipate (PBSA) copolymer during degradation in various environmental conditions. Polymers (Basel). 10:1-12.

Quecholac-Piña X, Hernández-Berriel MDC, Mañón-Salas MDC, Espinosa-Valdemar RM, Vázquez-Morillas A, 2020. Degradation of plastics under anaerobic conditions: a short review. Polymers (Basel). 12:1-18.

Ratto JA, Stenhouse PJ, Auerbach M, Mitchell J, Farrell R, 1999. Processing, performance and biodegradability of a thermoplas- 
tic aliphatic polyester/starch system. Polymer (Guildf). 40:6777-88

Ruggero F, Gori R, Lubello C, 2019. Methodologies to assess biodegradation of bioplastics during aerobic composting and anaerobic digestion: a review. Waste Manag. Res. 37:959-75.

Rychter P, Kawalec M, Sobota M, Kurcok P, Kowalczuk M, 2010. Study of aliphatic-aromatic copolyester degradation in sandy soil and its ecotoxicological impact. Biomacromolecules 11:839-47.

Sander M, 2019. Biodegradation of polymeric mulch films in agricultural soils: concepts, knowledge gaps, and future research directions. Environ. Sci. Technol. 53:2304-15.

SAPEA, 2020. Biodegradability of plastics in the open environment (Group of Chief Scientific Advisors, Ed.). European Commission Directorate-General for Research and Innovation, Brussels.

Scaringelli MA, Giannoccaro G, Prosperi M, Lopolito A, 2016. Adoption of biodegradable mulching films in agriculture: Is there a negative prejudice towards materials derived from organic wastes? Ital. J. Agron. 11:92-9.

Šerá J, Stloukal P, Jančová P, Verney V, Pekařová S, Koutný M, 2016. Accelerated biodegradation of agriculture film based on aromatic-aliphatic copolyester in soil under mesophilic conditions. J. Agric. Food Chem. 64:5653-61.

Sintim HY, Bary AI, Hayes DG, Wadsworth LC, Anunciado MB, English ME, Bandopadhyay S, Schaeffer SM, DeBruyn JM, Miles CA, Reganold JP, Flury M, 2020. In situ degradation of biodegradable plastic mulch films in compost and agricultural soils. Sci. Total Environ. 727:138668.

Solaro R, Corti A, Chiellini E, 1998. A new respirometric test simulating soil burial conditions for the evaluation of polymer biodegradation. J. Environ. Polym. Degrad. 6:203-8.

Someya Y, Kondo N, Mitsushiro S, 2007. Biodegradation of poly(butylene adipate-co-butylene terephthalate)/layered-silicate nanocomposites. J. Appl. Polym. Sci. 106:730-6.

Thompson AA, Samuelson MB, Kadoma I, Soto-Cantu E, Drijber R, Wortman SE, 2019. Degradation rate of bio-based agricultural mulch is influenced by mulch composition and biostimulant application. J. Polym. Environ. 27:498-509.
Toderi M, Francioni M, Seddaiu G, Roggero PP, Trozzo L, D'Ottavio P, 2017. Bottom-up design process of agri-environmental measures at a landscape scale: evidence from case studies on biodiversity conservation and water protection. Land Use Policy 68:295-305.

Tokiwa Y, Calabia BP, Ugwu CU, Aiba S, 2009. Biodegradability of plastics. Int. J. Mol. Sci. 10:3722-42.

Touchaleaume F, Martin-Closas L, Angellier-Coussy H, Chevillard A, Cesar G, Gontard N, Gastaldi E, 2016. Performance and environmental impact of biodegradable polymers as agricultural mulching films. Chemosphere 144:433-9.

Vanharova L, Julinova M, Slavik R, 2017. PVP based materials: biodegradation in different environments. Ecol. Chem. Eng. S 24:299-309.

$\mathrm{Xu}$ J, Guo BH, 2010. Poly(butylene succinate) and its copolymers: research, development and industrialization. Biotechnol. J. 5:1149-63.

Wang H, Wei D, Zheng A, Xiao H, 2015. Soil burial biodegradation of antimicrobial biodegradable PBAT films. Polym. Degrad. Stab. 116:14-22.

Wei R, Zimmermann W, 2017. Microbial enzymes for the recycling of recalcitrant petroleum-based plastics: how far are we? Microb. Biotechnol. 10:1308-22.

Yamamoto-Tamura K, Hiradate S, Watanabe T, Koitabashi M, Sameshima-Yamashita Y, Yarimizu T, Kitamoto H, 2015. Contribution of soil esterase to biodegradation of aliphatic polyester agricultural mulch film in cultivated soils. AMB Express 5:1-10.

Zhang M, Jia H, Weng Y, Li C, 2019. Biodegradable PLA/PBAT mulch on microbial community structure in different soils. Int. Biodeterior. Biodegrad. 145:104817.

Zumstein MT, Narayan R, Kohler HPE, McNeill K, Sander M, 2019. Dos and do nots when assessing the biodegradation of plastics. Environ. Sci. Technol. 53:9967-9.

Zumstein MT, Schintlmeister A, Nelson TF, Baumgartner R, Woebken D, Wagner M, Kohler HPE, McNeill K, Sander M, 2018. Biodegradation of synthetic polymers in soils: tracking carbon into $\mathrm{CO} 2$ and microbial biomass. Sci. Adv. 4. 